\title{
Análise do conceito de ciência em Bruno Latour nas obras $A$ Esperança de Pandora e Jamais Fomos Modernos
}

\author{
Pedro Miguel Feres Aua ${ }^{1}$ \\ Recebido em março de 2020 \\ Aceito em junho de 2020
}

\section{RESUMO}

Na segunda metade do século XX, o campo intelectual que se dedicava a pensar a ciência girava em torno de um questionamento: se a atividade científica e seus produtos seriam capazes ou não de encurtar um gap existente entre os polos humano e não humano, entre sujeitos e objetos. É nesse cenário que Bruno Latour, filósofo francês, propõe um entendimento inovador a respeito da separação moderna entre humanos e não humanos e, consequentemente, a respeito da prática científica. Em nosso trabalho, pretendemos discutir esse entendimento, que consiste na ideia de que, em realidade, nós jamais teríamos separado esses polos como parecíamos fazer. Realizaremos uma reflexão sobre ciência à luz de Bruno Latour nas obras Jamais Fomos Modernos e A Esperança De Pandora a fim de discutir seus principais pontos no que tange à prática científica. Concluiremos, analisando essas ideias para o entendimento do autor a respeito da modernidade, ilustrando como a ciência não é capaz de encurtar o suposto gap, pois este jamais existiu, pois, a própria atividade cerne do Ocidente, a atividade científica, opera em uma mistura de natureza e cultura, humanos e não humanos.

Palavras-chave: Ciência moderna; Latour; Não humanos; Natureza; Cultura.

\section{Analisys of Bruno Latour's concept of science in the books Pandora's Hope and We have Never Been Modern}

\begin{abstract}
In the final decades of the twentieth century, the intelectual fields studying science revolved around a question: if the scientific activities and its products were capable of shortening a gap between humans and non-humans, between subjects and objects. In this context, Bruno Latour, french philosopher, proposes an innovative understanding about the modern separation between humans and non-humans and, therefore, about the scientific activities. In this article we shall discuss this understanding, which shows the fact that we have never separated these two poles as we would seem to do. We shall carry out a discussion on science in accordance with Bruno Latour's works We Have Never Been Modern and Pandora's Hope in order to discuss his main arguments on the scientific activities. We shall conclude by analysing the autor's ideas applied to the concept of modernity, illustrating how science is not capable of shortening the supposed $g a b$, since it has never existed, because the West's central activity, the scientific activity, operates in a mix of nature and culture, of humans and non-humans.
\end{abstract}

Keywords: Modern science. Latour. Non-humans. Nature. Culture.

1 Graduando em Ciências Sociais pela Pontifícia Universidade Católica do Rio de Janeiro (PUC-Rio), bolsista PIBIC na pesquisa "Antropologia da ciência e tecnologia no campus da PUC-Rio" coordenada pelo doutor Felipe Süssekind Viveiros de Castro. Rio de Janeiro. Brasil. Contato: pedromferes@gmail.com. 


\title{
Introdução
}

$E_{m}$ nosso trabalho, pretendemos analisar o conceito de ciência em duas obras do sociólogo, antropólogo e filósofo francês Bruno Latour: A Esperança de Pandora e Jamais Fomos Modernos. Nosso objetivo será o de, a partir de uma breve contextualização das chamadas "guerras da ciência", inserir as ideias sobre ciência de Latour como uma alternativa às posições defendidas nesse conflito, as quais serão explicitadas adiante.

Em Jamais Fomos Modernos, Latour (1994) nos apresenta uma narrativa segundo a qual a modernidade ${ }^{2}$ seria fundada e definida por uma divisão entre o que ele denomina objetos e sujeitos, em outras palavras, uma clássica divisão entre natureza e cultura, os objetos em si e os sujeitos entre si³ (LATOUR, 1994). Tal divisão inaugura também uma divisão do trabalho intelectual entre ciências humanas e ciências da natureza 4 .

Identificamos nesse grande divisor o início de uma separação que se consagra no século XX e marca dois distintos posicionamentos acerca da atividade científica:

\begin{abstract}
Em 1959, C. P. Snow chamava a atenção para aquilo a que chamou as "duas culturas": a cultura científica por um lado, e a cultura literária e humanística por outro, separavam-se por um fosso de incomunicabilidade. Na sequência de várias tomadas de consciência deste problema, que tinha como consequência uma cada vez maior incompreensão e desconfiança das populações em relação às verdadeiras motivações do trabalho científico, apareceram autores que, seguindo as concepções de Kuhn' ${ }^{5}$, empreenderam uma tentativa de estudo do
\end{abstract}

2 Para Latour, o que define a modernidade é um processo de separação do que se entende por natureza do que se entende por sociedade. A modernidade não possui um marco temporal definitivo, mas podemos remontá-la a emblemática disputa entre Thomas Hobbes e Robert Boyle acerca da natureza do vácuo.

3 Entende-se por objetos em si os entes não dotados de agência, a princípio, mesmo que Latour reconfigure essa ideia em suas obras como veremos nas próximas seções. Já os sujeitos entre si denotam os entes dotados de agência e intencionalidade, capazes de estabelecer relações sociais intencionadas.

4 Por ciências humanas, entendemos o trabalho intelectual acadêmico voltado para o estudo do ser humano e da sociedade. Por ciências da natureza, entendemos o estudo da natureza, nesse contexto entendida como uma realidade existente independente da cultura. Esta, classicamente, um pano de fundo para as ações humanas.

5 Thomas Kuhn, consagrado filósofo da ciência, inovou esse campo de estudos com a publicação de seu livro A Estrutura das Revoluções Científicas (1962), no qual aponta para o fato de que a ciência trabalha sob a noção de paradigma, um conjunto de métodos, regras e formas de ler os problemas científicos que 
trabalho científico, valorizando os seus aspectos irracionais, a sua estreita relação com fenómenos históricos, sociais e culturais, culminando numa concepção diametralmente oposta à tradicional do conhecimento científico: a natureza não é a causa dos enunciados científicos, mas sim a sua consequência (GIL, 2014, p. 298).

São essas "duas culturas" que iniciam um embate mais severo na década de 1990 dando origem ao fenômeno que ficou conhecido como guerras da ciência. ${ }^{6}$ Ficamos, novamente, com Cíntia Garcia Gil:

Na segunda metade do século vinte surgiu uma querela entre por um lado os cientistas e investigadores das ciências naturais, sobretudo da área da física, por outro lado investigadores, teóricos e críticos culturais que trabalham e defendem a perspectiva dos chamados science studies. Esta guerra das ciências ${ }^{7}$ tem vários matizes, e tem a ver com diferenças de cariz epistemológico, metodológico, e até axiológico (GIL, 2014, p. 297).

O debate girava em torno do questionamento acerca de se a ciência era capaz de encurtar um suposto gap $^{8}$ existente entre humanos e não humanos. Designaremos por realistas os que afirmam que sim, ao passo que os que respondem negativamente designaremos como relativistas9 (PATERNOSTER, 2016). Os primeiros nos remetem à

orienta uma comunidade de cientistas. Dentro dessa noção, Kuhn defende que a ciência não é puramente racional e trabalha, também, com certo dogmatismo, uma vez que o paradigma constitui uma diretriz geral raramente questionada.

6 Um caso emblemático desse fenômeno foi o que ficou conhecido como caso Alan Sokal. Este físico norteamericano submeteu um artigo, em 1996, à revista Social Text, propondo que a gravidade quântica, um fenômeno físico da mecânica quântica, seria uma construção linguística e cultural. O artigo foi publicado e, mais tarde, o autor revelou que se tratava de uma farsa: o texto fora escrito sem rigor e sem coerência lógica. Muitos interpretaram o evento como a prova de que, utilizando as palavras corretas, os estudos da chamada pós-modernidade, publicariam qualquer coisa.

7 As guerras das ciências seriam, portanto, uma disputa entre alguns cientistas das áreas de humanidades e das ciências da natureza. Ambos reivindicando uma definição do que seria a atividade científica. Para maior aprofundamento, recomendamos o artigo de Bruno Latour para a Folha de São Paulo intitulado A guerra das ciências.

8 Por muitos séculos, os filósofos entenderam que a natureza seria definida em oposição aos seres humanos. Estes, dotados de subjetividade e cultura, tinham como palco de suas ações um cenário cuja leis seriam imutáveis e universais. O gap a que nos referimos diz respeito à distância, em termos de conhecimento, entre a sociedade e a natureza, ou seja, a princípio não conhecemos as leis que a governam, não temos acesso direto a ela. A questão maior sobre a ciência é se ela possui a capacidade de nos fazer conhecer melhor a natureza tal como ela seria.

9 A negação de uma ciência estritamente conectada com a ideia de verdade, ou seja, uma relativização da noção de ciência, já podia ser encontrada em autores como Karl Popper e seu entendimento de que nenhuma teoria pode ser confirmada. O máximo que poderíamos dizer é que não foi falseada (POPPER, 1963). Uma relativização mais radical pode ser encontrada nas obras de Paul Feyerabend. Esse, filósofo da ciência, defende que não deve haver um método científico rígido. Pelo contrário, a ciência se 
ideia de que a natureza possui um conhecimento imutável e universal à espera de ser descoberto, enquanto os segundos nos trazem à mente a ideia de que a ciência é apenas um discurso e uma prática social como quaisquer outros ${ }^{10}$.

A seguir, veremos como a filosofia proposta por Bruno Latour pode ser uma alternativa que foge a essa dicotomia. Para isso, primeiro analisamos um caso específico desenvolvido pelo autor em A Esperança de Pandora (2017), o de Louis Pasteur e o levedo e, em seguida, saltamos para um outro caso específico: o da bomba de ar e o conflito entre Thomas Hobbes e Robert Boyle, expresso em Jamais Fomos Modernos. Para concluir, ilustramos como essas ideias ficam em quadro geral e como elas influenciam, segundo o próprio autor, nossa visão acerca da modernidade.

\section{O caso emblemático de Louis Pasteur e o levedo}

Em A Esperança de Pandora, Latour (2017) nos apresenta um caso emblemático para ilustrar seu entendimento de ciência: o caso de Louis Pasteur ${ }^{11}$ e a fermentação.

Nossa história, contada pelo filósofo francês a partir de um dos textos de Pasteur, remonta a meados do século XIX, quando o processo de fermentação era explicado por mecanismos puramente químicos. Era evidente para a maioria dos cientistas que não havia nada de biológico naquele processo, nenhum organismo vivo (LATOUR, 2017): "se algum fermento está envolvido, ele nada mais é que um subproduto quase invisível de um mecanismo puramente químico de fermentação ou, pior ainda, uma impureza indesejável capaz de prejudicar e deter a fermentação." (LATOUR, 2017, p. 139).

Isso acontece, contudo, no início do artigo de Pasteur, sinaliza Latour (2017). No fim, acompanhamos uma total transformação do fermento. De mero subproduto e massa desforme, o novo elemento entra em cena com um papel diferente: ele se consagra

\footnotetext{
beneficiaria de uma certa anarquia metodológica, isto é, uma maior frouxidão metodológica (FEYERABEND, 1993).

1o Não negamos que existem outros posicionamentos anteriores a Latour. O que pretendemos dizer é que, no debate das guerras das ciências, as posições defendidas podem ser resumidas ao que denominamos realismo e relativismo.

11 Importante químico do século XIX. Responsável por criar o processo que veio a ser chamado de pasteurização, um procedimento para impedir que leite e vinho causem doenças.
} 
como um ator $^{12}$. Em vez de ser mera consequência de uma matéria orgânica, o fermento passa a nutrir-se dela (LATOUR, 2017).

É interessante notar que ocorre uma mudança na ontologia daquele ente, o fermento, ou seja, ele não é mais uma massa cinzenta sem nome à qual a comunidade científica pouco dava atenção, ele se eleva a uma nova categoria capaz de produzir modificações na sociedade e nos próprios cientistas. Antes subproduto, agora a fermentação passaria a ser um novo procedimento: "A prática lenta e incerta com uma explicação obscura transforma-se num conjunto ágil e compreensível de novos métodos dominados por Pasteur" (LATOUR, 2017, p.145).

$\mathrm{O}$ que nos interessa dessa história narrada pelo químico e comentada pelo filósofo é, em primeiro lugar, a agência dos não humanos. Latour (2017) sinaliza para como o fermento modifica Pasteur para sempre e vice-versa. O cientista passaria a ser um personagem consagrado na história das ciências, e o fermento passaria a fazer parte de uma operação química como protagonista. Isso propõe um entendimento novo do suposto gap existente entre humanos e não humanos. Nessa interpretação, a ciência não mais precisaria encurtá-lo, uma vez que ela trabalha bem no meio desse abismo.

Além disso, o filósofo, inicialmente, fala em dois testes: um primeiro, no qual o químico descreve seu procedimento, incluindo suas interferências, a fim de fazer com que o fermento entre em ação; e um segundo, no qual se refere a uma situação que envolve materiais como tubos de ensaios e assistentes de laboratório (LATOUR, 2017). Mas não é só isso que é importante nessa cena. Há mais um elemento primordial. Há um terceiro teste. Pasteur terá, argumenta Latour (2017), que defender sua nova tese frente a seus colegas. Isso consagrará o fermento como independente do cientista, ou entrará para a história das ciências como mais uma tentativa desviada de acessar-se a natureza, porém desviada pelos preconceitos humanos. Os três juntos consagram um experimento $^{13}$, na visão de Latour.

12 A palavra mais utilizada atualmente pelo autor é actante. Podemos entendê-lo como um ente dotado de agência, ou seja, capaz de produzir e modificar conteúdos. Acreditamos que, conforme o andamento do texto, fique mais claro, com o exemplo do fermento e Pasteur, o que define um ator.

$13 \mathrm{O}$ experimento, em geral, era entendido na filosofia da ciência como um teste capaz de atestar os resultados teóricos esperados, ou até mesmo antecipar novos resultados teóricos. Com Latour, o experimento caracteriza-se também por envolver um processo de intervenções da mão humana na 
Se o experimento é bem-sucedido, ou seja, se os três testes são superados, então temos, de fato, um novo Pasteur e um novo fermento. Ambos não possuem valores metafísicos diferentes na filosofia latouriana, ambos são capazes de agência, são atores.

Assim, os não humanos ou "os intermediários não são mais os véus diante de nossos olhos que nos impedem de apreender a realidade tal como ela é; são as traves que estendemos sob os nossos pés para chegar ao real!" (CAVALCANTI, 2002).

Passando isso para uma visão mais geral, podemos entender que a ciência é, na visão do autor, uma construção, uma fabricação. Porém, não no sentido vulgar da palavra, mas sim no sentido de que atores humanos e não humanos, de mesmo valor metafísico, recombinam-se, agem mutuamente uns sobre os outros transformando-se para sempre. Além disso, quanto mais se multiplicam esses atores, mais confiável é a rede na qual estão inseridos. É nesse sentido que a ciência se torna uma atividade poderosa: ela inclui uma rede bastante vasta de atores, sejam eles cientistas, artigos, átomos, tubos de ensaio e empresas financiadoras.

Um outro fato interessante a ser mencionado é a historicidade dos micróbios de Pasteur. Na concepção de Latour (2017), os micróbios não existiam antes de Pasteur descobri-los, não da mesma maneira. Em verdade, a descoberta é o que o autor sinaliza como acontecimento ou evento. Ficamos com Roger Sansi:

\footnotetext{
Os experimentos de Pasteur mostraram que a fermentação é iniciada por um organismo vivo previamente desconhecido: a bactéria. O experimento não era apenas o resultado da vontade do cientista, Pasteur, que "procurou" descobrir as bactérias: ele foi resultado de um complexo processo que demandou ação de todos os lados: de Pasteur, mas também da bactéria que realmente iniciou a fermentação, a Academia de Ciências, a qual aceitou os resultados do experimento, e um rol de outros actantes ${ }^{14}$ humanos e não humanos (ESTEVAM, SANSI, 1993, p. 241).
}

E mais adiante:

Dizer que "os actantes são eventos" não significa que entidades tais como Pasteur, as bactérias ou a Academia não existam antes do evento, mas que elas

natureza, assistentes de laboratório não humanos e, por fim, um esforço para convencer os colegas de que os acontecimentos atestados no experimento são parte da realidade e independem da ação humana. $14 \mathrm{O}$ termo actantes é um sinônimo para atores, conceito de Latour que utilizamos nesse artigo. 
não existem do mesmo modo, como actantes; o evento as transforma umas em relação às outras, há um antes e um depois (ESTEVAM, SANSI, 1993, p. 241).

Nesse sentido, os eventos não são a descoberta de uma verdade, mas fazem-na acontecer, no sentido em que produzem uma nova rede de associações como novos cientistas, novas indústrias, empresas e até mesmo novas políticas (ESTEVAM, SANSI, 1993).

Vale lembrar que os eventos definem não só uma história adiante de si, mas uma história anterior: uma vez descobertos os micróbios, eles sempre estiveram lá. Experimentos que os ignoraram continham em si algum erro de cálculo ou de experimentação.

\section{Boyle e Hobbes: um caso particular}

Mais conhecido por suas teorias sobre o Estado, Thomas Hobbes também possuía uma física própria descrita, em The Leviathan and the Air-pump, de Steven Shapin e Simon Schaffer. Analogamente, o físico Robert Boyle também possuía uma física, obviamente, e uma teoria social. Utilizaremos este livro ${ }^{15}$ para fazer uma análise da física de Boyle, em especial sua demonstração da existência do vácuo, à luz da análise feita por Latour sobre o caso Pasteur.

Hobbes era um plenista, ou seja, era partidário da ideia de que não deveria haver vácuo pois a natureza teria horror a ele, como postulou Aristóteles em seu livro Física. Nesse sentido, qualquer espaço vazio seria imediatamente preenchido pela matéria.

Contudo, Hobbes possuía o antagonista Boyle. O irlandês produziu um dispositivo experimental que marcou a história das ciências: a bomba de ar. Esta seria um dispositivo cuja finalidade inicial era a de expulsar o ar de um determinado recipiente.

Comecemos com o que Shapin e Schaffer nos apresentam como questão de fato (matter of fact) (SHAPIN; SCHAFFER, 2011). Essa noção diz respeito a um elemento

15 SHAPIN, Steven; SCHAFFER, Simon. Leviathan and the Air-Pump: Hobbes, Boyle, and the Experimental Life. Princeton, N.J: Princeton University Press, 2011. 
disponível na natureza que é possível ser acessado mediante experimentos. A solidez de uma questão de fato consistiria em sua suposta independência da ação humana. Claro que podemos, por vezes, negar que algo é uma questão de fato, mas quando o estamos fazendo, não estamos negando-a como essência, mas sim negando que o elemento em questão não se classifica como uma questão de fato (SHAPIN; SCHAFFER, 1985).

O que Robert Boyle teria feito segundo essa visão é acessar uma questão de fato por meio de um experimento, ou seja, a exclusão de si de uma narrativa, na qual a natureza sai como principal protagonista.

Essa não é, entretanto, a visão que os autores nos apresentam no final de seu livro. Nos trechos finais, Shapin e Schaffer (2011) buscam dar uma resposta à natureza do conhecimento. Seria ele parte de um plano universal e imutável à espera de ser conhecido por nós? Ou estaria ele apenas na mente humana? Os autores, afirma Latour (1994), acabam por atribuir a vitória a Hobbes: o conhecimento estaria na verdade dentro de nossas mentes, assim com as leis da natureza.

Contudo, esta não seria a perspectiva de Latour. $\mathrm{O}$ autor sob análise não concordaria nem com a visão das questões de fato nem com uma vitória absoluta de Hobbes sobre Boyle. Na verdade, em Jamais Fomos Modernos, o autor nos dá uma breve análise a partir de sua teoria a respeito da bomba de ar.

Para o francês, não há um conhecimento "lá fora” à espera de ser decodificado pelos experimentos humanos, o processo não ocorre dessa forma. O que houve no laboratório de Boyle foi uma interação, muito similar à que vimos no caso de Pasteur, uma rede, no sentido de que vários atores entraram em cena e se rearranjaram, influenciando-se mutuamente. Tanto a bomba de ar quanto a pena de galinha utilizada para refutar Hobbes, ${ }^{16}$ tanto o assistente de Boyle que acionava a bomba quanto as testemunhas do experimento são atores. ${ }^{17}$

16 Para refutar a teoria hobbesiana de que haveria uma substância, o éter, que preenchia os espaços entre os corpos, Boyle insere uma pena de galinha no interior da bomba de ar a fim de detectar seu movimento causado pelo suposto éter. Para a tristeza de Hobbes, a pena permanece parada (LATOUR, 1994).

17 Vale ressaltar que este é o princípio da Teoria-Ator-Rede, desenvolvida por Latour em parceria com outros intelectuais, como o sociólogo Michel Callon. Nessa teoria, humanos e não humanos são tratados em pé de igualdade como agentes. Agrupados, estabelecem uma rede de conexões e mútua influência. Uma crítica a esse modelo é a de que não se estabelece uma hierarquia entre os atores, como vemos, no caso, a equivalência em termos de ação entre um fermento e um ser humano (INGOLD, 2011). 
O experimento no sentido em que Latour emprega é o movimento que Boyle faz, juntamente à bomba de ar e a todos esses autores. Desde sua parte material (o acionamento da bomba) até o convencimento de toda uma comunidade de que a experiência ocorreu independentemente de sua vontade, mesmo que ele puxasse as cordas das marionetes.

Na visão do filósofo, não podemos assumir que a sociedade possui maior valor explicativo do que a natureza. Temos que ser simétricos em relação a ambos. Explicamos isso no próximo item, sintetizando o papel da ciência para Latour.

\section{A Grande Divisão cai por terra}

Tendo analisado esse caso emblemático e sintetizado as principais conclusões do autor, regressamos a uma de suas obras anteriores: Jamais Fomos Modernos ${ }^{18}$.

A metodologia de Latour acerca da ciência concentra-se em analisá-la enquanto está sendo praticada, e não apenas seu produto. $\mathrm{O}$ caso acima ilustra bem isso. Escolhemo-lo para ilustrar uma tese maior.

Em Jamais Fomos Modernos, Latour (1994) defende a tese de que instauramos, enquanto modernos, duas Grandes Divisões. A segunda se dá entre “nós”, ocidentais¹9, e “eles”, não-ocidentais. ${ }^{20}$ Contudo, essa divisão derivaria de uma outra, a que mencionei anteriormente: entre natureza e cultura, objetos e sujeitos.

No decorrer do livro, Latour (1994) argumenta que, em verdade, nós nunca separamos natureza e cultura como parecíamos fazer. Na verdade, nossas práticas sempre as misturaram num processo que podemos chamar de mediação enquanto

18 LATOUR, Bruno. Jamais Fomos Modernos. Rio de Janeiro: Ed 34, 1994.

19 Entendemos por ocidental uma cultura específica que se expandiu com os processos de colonização. Essa cultura caracteriza-se por ser herdeira de uma tradição filosófica grega, um direito romano e uma moral judaico-cristã. Evidente que podemos aqui estar fazendo parecer com que o que chamamos de ocidente é um bloco demasiado homogêneo, mas para os fins de nossa argumentação, essa consideração é suficiente.

20 Aqui vale lembrar da antropologia simétrica, proposta por Latour, na qual analisam-se práticas modernas, como a indústria, o laboratório ou sistemas de metrô com o mesmo olhar que se analisaria uma aldeia indígena. Assim, se o antropólogo que estuda os Ashuar descreve suas técnicas de caça e plantio conectando humanos e não humanos, da mesma forma deve proceder o sociólogo da ciência que estuda um laboratório nos Estados Unidos, cujo caso emblemático é descrito etnograficamente por Latour (LATOUR, 1997). 
apresentavam seus produtos purificados, mediante o processo de purificação (LATOUR, 1994). Pensemos nos casos analisados acima. Eles são nada mais do que, em uma visão latouriana, a recombinação de humanos e não humanos exercendo suas ações uns sobre os outros para, no fim, apresentarem-se como purificados. ${ }^{21}$

Para além dessas terminologias, interessa-nos notar algo expresso pelo autor em seu livro: a noção de que a ciência moderna ${ }^{22}$ é o que nos faz pensar, enquanto ocidentais, como especiais:

Se os ocidentais houvessem apenas feito comércio ou conquistado, pilhado e escravizado, não seriam muito diferentes de outros comerciantes e conquistadores. Mas não, inventaram ciência, esta atividade em tudo distinta da conquista e do comércio, da política e da moral (LATOUR, 1994, p. 97).

Porém, como vimos nos exemplos de Pasteur e de Boyle e Hobbes, a ciência consiste, essencialmente, em uma mistura de humanos e não humanos, que só mais tarde se apresentam como puros e independentes.

Portanto, se a atividade própria que funda o abismo entre humanos e não humanos é, na verdade, uma mistura de ambos, então essa divisão jamais deve ter existido como acreditávamos (LATOUR, 1994).

É nesse sentido que entendemos que Latour oferece um caminho valioso para o embate entre realistas e relativistas, pois foge à polarização que o orienta ao sugerir uma explicação intermediária. Segundo sua visão, a ciência não é capaz de encurtar um gap entre humanos e não humanos, pois este jamais deve ter existido.

\section{Conclusão}

Com os casos mostrados acima e com a sintetização das ideias do autor sobre ciência, esperamos ter deixado claro o quanto seu posicionamento acerca da prática

\footnotetext{
21 Utilizamos, aqui, a terminologia de Latour. O termo diz respeito a um ente que, apesar de, em sua construção, ter elementos que independem da ação humana e elementos sociais (de interferência humana), no fim das contas, apresenta-se como pertencente apenas à natureza ou à sociedade.

22 Segundo Isabelle Stengers, filósofa belga, a ciência moderna nasce e opera na exclusão da não ciência, isto é, na desqualificação de todo conhecimento a respeito do mundo que não seja considerado científico (STENGERS, 2002).
} 
científica constitui uma alternativa aos ideais defendidos nas guerras da ciência, principalmente ao propor essa atividade como uma mistura de humanos e não humanos que se modificam mutuamente e nos entregam novos entes.

Vale ressaltar que não é o objetivo do autor rejeitar a modernidade ou a constituição (separação entre sujeitos e objetos) que a define. Mas sim abrir a caixa-preta que ela oculta, ou seja, revelar o caminho do meio, onde se encontram os híbridos de sujeito e objeto, que ela esconde (LATOUR, 1994). Os estudos de ciência são um bom exemplo disso, já que a atividade cerne do ocidente é a própria atividade científica.

Revelados os híbridos, a ideia de uma ciência descolada da política e da sociedade é enfraquecida. Um dos problemas iniciais do autor é resolvido. Contudo, é perfeitamente possível questionar o que seria então uma boa ciência ou um bom cientista. Além disso, dentro da teoria apresentada, a voz dos cientistas parece ter sido enfraquecida, sendo plausível, então, questionar até que ponto esse enfraquecimento fortaleceu discursos que combatem noções amplamente aceitas no meio científico. Por conta de perguntas como essas e dos desafios que o tempo presente fornece, o autor constantemente reestrutura seu pensamento, mas guardando sempre a contribuição de propor um entendimento inovador dentro do debate polarizado das guerras da ciência.

\section{Referências}

CAVALCANTI, Vanessa. Guerra das Ciências: Análise das contribuições de Bruno Latour. 2002. Revista de História Regional 7(2):197-205.

ESTEVAM, Alessandra; SANSI, Roger. O evento Latour. In: Cadernos de Campo (São Paulo, 1991), v. 27, n. 1, p. 233-254, 2018.

FEYERABEND, Paul. Against method. Verso. 1993.

GIL, Cíntia Garcia. A guerra das ciências. Filosofia, Revista da Faculdade de Letras da Universidade do Porto, [S.1.], v. 22, 2014. ISSN 2183-6892. Disponível em: <http://ojs.letras.up.pt/index.php/filosofia/article/view/515/508>. Acessado em: 23 de agosto. 2019.

INGOLD, Tim. Being Alive: Essays on Movement, Knowledge and Description. London. New York: Routledge, 2011. 
LATOUR, Bruno. A guerra das ciências. Folha de São Paulo, c. MAIS. 1998. Disponível em: <https://www1.folha.uol.com.br/fsp/mais/fs15119803.htm>. Acessado em: 28 de janeiro. 2020.

Jamais Fomos Modernos. Rio de Janeiro: Ed 34, 1994.

A Esperança de Pandora. São Paulo: editora UNESP, 2017.

; WOOLGAR, S. A Vida de Laboratório: a produção dos fatos científicos. Rio de Janeiro: Relume-Dumará, 1997.

PATERNOSTER, Bruce. In: theorizing at Rowan. Glassboro, Nova Jersey, EUA. Bruno Latour and the Social Construction of Scientific Knowledge. Resumo. 2016.

POPPER, Karl. Conjectures and Refutations: The Growth of Scientific Knowledge. Routledge, 2014.

SHAPIN, Steven; SCHAFFER, Simon. Leviathan and the Air-Pump: Hobbes, Boyle, and the Experimental Life. Princeton, N.J: Princeton University Press, 2011.

STENGERS, Isabelle. A Invenção das Ciências Modernas. São Paulo: Editora 34, 2002. 